\title{
Extreme Temperature Trends in the Beninese Niger River Basin (Benin)
}

\author{
Yarou Halissou ${ }^{1,2 *}$, Alamou Adéchina Eric ${ }^{2,3}$, Obada Ezéchiel ${ }^{2,3}$, Biao Ibukun Eliézer²,4 \\ ${ }^{1}$ Chaire Internationale de Physique Mathématique et Application (CIPMA-CHAIRE UNESCO), Université d'Abomey-Calavi \\ (UAC), Cotonou, Benin \\ ${ }^{2}$ Laboratoire de Géoscience de l'Environnement et Application (LaGEA/UNSTIM), Abomey, Benin \\ ${ }^{3}$ Ecole Nationale Supérieure des Travaux Publics (ENSTP), Université Nationale des Sciences, Technologies, \\ Ingénierie et Mathématiques (UNSTIM), Abomey, Benin \\ ${ }^{4}$ Ecole Nationale Supérieure de Génie Mathématique et Modélisation, Université Nationale des Sciences, Technologies, \\ Ingénierie et Mathématiques (UNSTIM), Abomey, Benin \\ Email: ^halissou.yarou@gmail.com, ericalamou@yahoo.fr, e.obada83@yahoo.fr, biaoeliezer@yahoo.fr
}

How to cite this paper: Halissou, Y., Eric, A. A., Ezéchiel, O., \& Eliézer, B. I. (2021). Extreme Temperature Trends in the Beninese Niger River Basin (Benin). American Journal of Climate Change, 10, 371-385. https://doi.org/10.4236/ajcc.2021.104018

Received: August 23, 2021

Accepted: October 16, 2021

Published: October 19, 2021

Copyright (c) 2021 by author(s) and Scientific Research Publishing Inc. This work is licensed under the Creative Commons Attribution International License (CC BY 4.0).

http://creativecommons.org/licenses/by/4.0/

\begin{abstract}
In the context of climate change, the study of the variability of the climatic extremes in several regions of the world is of capital importance. This study has as main objective to analyze the variability of extreme temperature events in the Beninese basin of the Niger River for the recent and the near future. To achieve this objective, seven (07) extreme temperature indices based on historical daily temperature observations (1976 to 2019) and REMO RCM simulation outputs of RCP4.5 and RCP8.5 scenarios (2021-2050) were calculated. The obtained results were represented by calculating the means for each index and analyzing the trends and their significance by the Mann-Kendall method. The results show that the indices of extreme temperature intensity (TNn, TXx, and DTR), and those related to the frequency of warm sequences (WSDI, TN90p and TX90p) have experienced a significant increase in the past. This increase will continue until 2050. In contrast, the cold sequence frequency index (CSDI) decrease over the historical period as well as over the future period. These indices show much more change with the RCP8.5 scenario than with the RCP4.5 of the REMO climate model. Only the TXx and CSDI indices show statistically significant changes at all stations.
\end{abstract}

\section{Keywords}

Temperatures, Extreme, Climatic Variations, Beninese Niger River Basin

\section{Introduction}

Climate is a very complex part of the Earth's "system" (Saurwein, 2016). It is 
made up of many factors (physical, chemical, and biological elements in particular) and can vary greatly in different regions of the world (e.g., desert, polar, tropical, and other types of climate) (Saurwein, 2016). Climate change is now widely recognized by the scientific community (IPCC, 2013), especially because of the socio-economic consequences that drive these changes (Frei, 2008; Rajczak, 2016). In human history, the need to understand climate change has never been more urgent and important than in the 21st century (Gnanglè et al., 2011). Indeed, deforestation and species extinction are relatively more important and living conditions have become more precarious especially in tropical Africa (Bush \& Flenley, 2007). This area, whose economy is essentially based on agriculture, is not without sensitivity (IPCC, 2007).

West Africa is a region where people are always faced with high climate variability. In addition to this variability, climate change resulting from anthropogenic greenhouse gas emissions adds to these challenging conditions (Badara \& Camara, 2017). The impact of these gases on climate change is now being assessed through a series of climate simulations over past and future periods (Obada, 2017). For example, we have the future climate simulation scenarios A1B, A2 and B1 which are the most used in impact studies (Haidu, 2009). Thus, the study of climate appears to be of capital interest for the understanding of events but also because of the very negative consequences that a change in variables could have on societies (for example sea level rise).

In fact, explaining and modeling these climate variations at different scales in time and space have become a challenge for climate scientists (AMMA ISSC, 2005; Janicot et al., 2008). This has led the IPCC to introduce emission scenarios to study climate since the 1990s (Leggett et al., 1992). The main objective of this research is to analyze past and future extreme temperatures in the Beninese Niger River basin.

\section{Methodology}

\subsection{Study Area and Data}

Located in the extreme north of Benin (Figure 1) with an area of approximately $48,000 \mathrm{~km}^{2}$, the Beninese Niger River basin occupies $42 \%$ of the total area of Benin $\left(114,763 \mathrm{~km}^{2}\right)$. It is located between latitudes $10^{\circ}$ and $12^{\circ} 30^{\prime}$ North and longitudes $1^{\circ} 32^{\prime}$ and $3^{\circ} 50^{\prime}$ East, and includes the Mékrou, Alibori and Sota sub-basins.

This study required the collection of daily maximum and minimum temperature data recorded from 1976 to 2019 at three (03) synoptic stations installed around the Benin River basin (Figure 1). These data are collected from National Agency of Meteorology (Météo-Bénin). These observed temperatures are complemented by the temperatures of the simulation outputs of the REMO Regional Climate Model. The latter is one of the regional climate models that best responds over the study basin (Badou, 2016). The model data combine historical temperatures over the period 1951 to 2005 and outputs from the different 


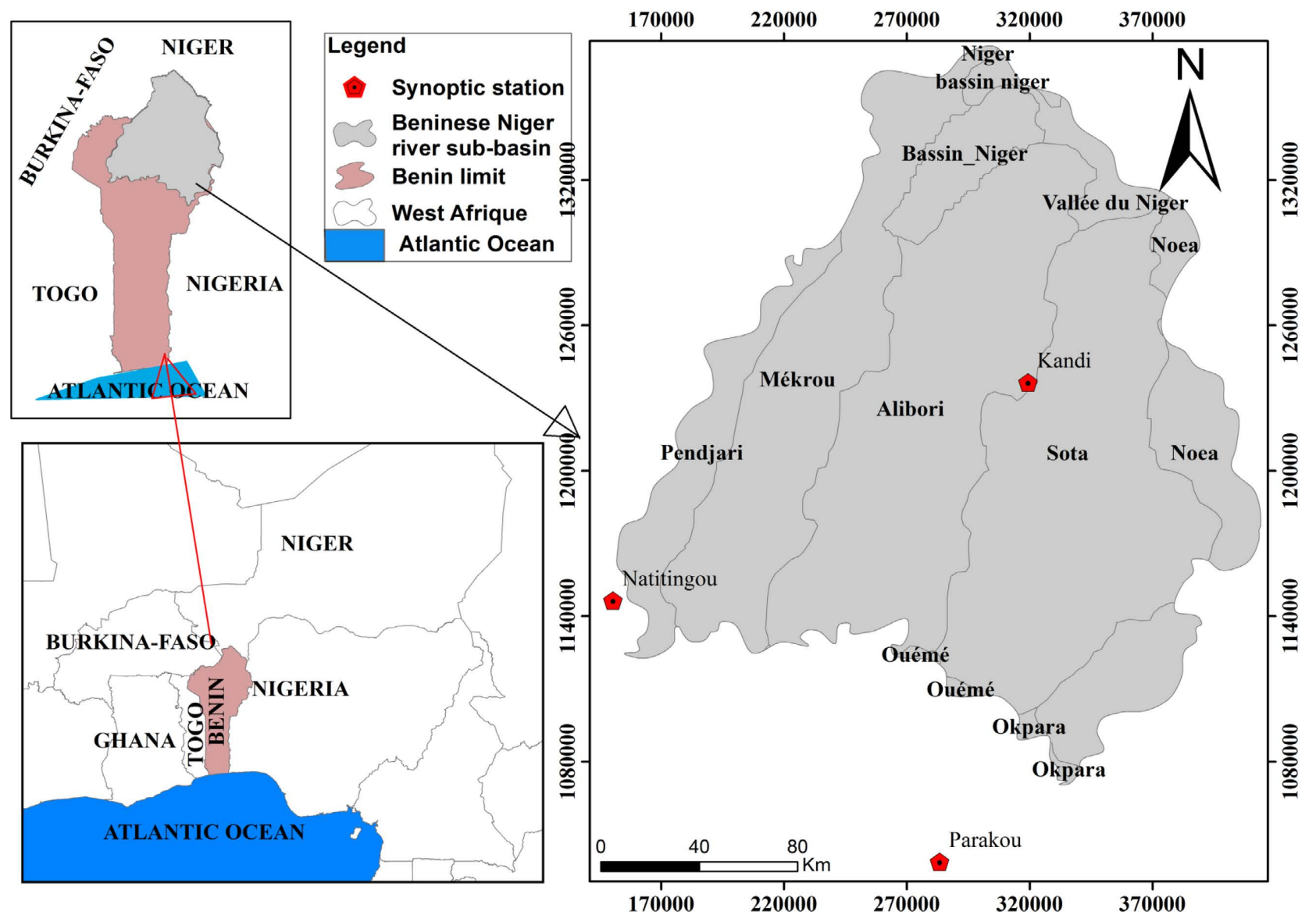

Figure 1. Study area.

RCP4.5 and RCP8.5 climate change scenarios from 2006 to 2050. These REMO climate model scenario data are interpolated from the grid to the points (stations). They are thus corrected by the method described in the methodology before the extraction and calculation of future indices.

The data are from the CORDEX project (http://wcrp.ipsl.jussieu.fr/SF_RCD_CORDEX.html). The model characteristics are shown in Table 1.

\subsection{Methods Used}

Extreme climate indices are defined from daily data. It is thus important to proceed to a good constitution of the daily series.

The quality control test called "Data QC" (Zhang \& Yang, 2004) was employed. This performance test follows two procedures: 1) replace all missing values (by code -99.9 ) according to the international format; 2) replace all unreasonable values by NA. These values include cases where daily maximum temperatures are lower than daily minimum temperatures (Zhang \& Yang, 2004).

A bias correction is generally performed on the outputs of climate models for the majority of climate change impact studies. This correction is generally 
Table 1. Characteristics of the RCM used.

\begin{tabular}{ccccccc}
\hline Model & Institution & $\begin{array}{c}\text { Forcing } \\
\text { MCG }\end{array}$ & $\begin{array}{c}\text { Horizontal } \\
\text { resolution }\end{array}$ & $\begin{array}{c}\text { Vertical } \\
\text { level }\end{array}$ & Simulations & Reference \\
\hline REMO & CSC & MPI-ESM-LR & $50 \mathrm{~km}$ & 27 & $1951-2100$ & $\begin{array}{c}\text { Jacob et al. } \\
(2007)\end{array}$ \\
\hline
\end{tabular}

uni-varied and corrects each variable of interest independently of the others. There are a large number of bias correction methods. The bias correction method used in this research is called "Delta change" (DC).

The DC method is the simplest and most widely used of the bias correction methods (Graham et al., 2007; Moore et al., 2008; Sperna Weiland et al., 2010) and consists of scaling the observations to obtain the corrected simulations. It is a modest method in which the parameters are usually corrected with an addictive factor for temperature (Equation (1)) (Lafon et al., 2013).

$$
x_{c o r, i}=x_{s, i}+\mu_{s}-\mu_{b}
$$

where $x_{c o r, i}$ represents the corrected temperature of day $i ; x_{s, i}$ the simulated temperature of day i. $\mu_{b}$ et $\mu_{s}$ are the average of the observed data for baseline period and the average of the simulated data respectively.

Seven (07) extreme temperature indices were used to characterize the past and future evolutions of extreme temperature in the study area (Table 2). These indices are: maximum of daily maximum temperatures (TXx), minimum of daily minimum temperatures (TNn), hot nights (TN90p), hot days (TX90p), heat duration index (WSDI), cold duration index (CSDI) and daytime temperature (DTR)

These temperature indices can be classified into two (02) groups. The first group is related to temperature intensity (TXx, TNn, and DTR). TXx and TNn characterize respectively warm and cold conditions. The second group is constituted by TX90p, TN90p, WSDI and CSDI; and is related to extreme temperature frequencies. TX90p, TN90p and WSDI are the hot extreme temperature indices and CSDI is a cold extreme temperature index.

The analysis of trends and their statistical significance were carried out from 1976 to 2019 by the Mann-Kendall method. Quantifying the effects of future changes in extreme temperature is an important requirement for assessing the vulnerability of hydrological systems to climate change. In this study, future changes (2021-2050) related to baseline period (1990-2019) were evaluated using Equation (2). The projected period is 2021-2050.

$$
\text { Change }=\frac{\bar{x}_{p}-\bar{x}_{r}}{\bar{x}_{r}} \times 100
$$

where $\bar{x}_{p}$ is the average of the index over the projected period and $\bar{x}_{r}$ its average over the reference period.

The Student $\mathrm{t}$-test was used to determine whether there is a significant difference between $\bar{x}_{p}$ and $\bar{x}_{r}$. 
Table 2. List of used temperature indices.

\begin{tabular}{|c|c|c|c|}
\hline Index & Name & Definition & Unit \\
\hline $\mathrm{TXx}$ & Max Tmax & maximum value of daily maximum temp & ${ }^{\circ} \mathrm{C}$ \\
\hline TNn & Min Tmin & Monthly minimum value of daily minimum temp & ${ }^{\circ} \mathrm{C}$ \\
\hline TN90p & Warm nights & Percentage of days when TN $>$ 90th percentile & Days \\
\hline TX90p & Warm days & Percentage of days when TX $>$ 90th percentile & Days \\
\hline WSDI & $\begin{array}{l}\text { Warm spell } \\
\text { duration } \\
\text { indicator }\end{array}$ & $\begin{array}{l}\text { Annual count of days with at least } 6 \\
\text { consecutive days when TX }>90 \text { th percentile }\end{array}$ & Days \\
\hline CSDI & $\begin{array}{l}\text { Cold spell } \\
\text { duration } \\
\text { indicator }\end{array}$ & $\begin{array}{l}\text { Annual count of days with at least } 6 \text { consecutive } \\
\text { days when } \mathrm{TN}<10 \text { th percentile }\end{array}$ & Days \\
\hline DTR & $\begin{array}{l}\text { Diurnal } \\
\text { temperature } \\
\text { range }\end{array}$ & $\begin{array}{l}\text { Monthly mean difference between } \\
\text { TX and TN }\end{array}$ & ${ }^{\circ} \mathrm{C}$ \\
\hline
\end{tabular}

\section{Results}

\subsection{Observed Trends of Extreme Temperature Indices}

The TXx index in the Beninese basin of the Niger River from 1976 to 2019 varied between $41.2^{\circ} \mathrm{C}$ and $43.9^{\circ} \mathrm{C}$ at Kandi with an average of $42.23^{\circ} \mathrm{C}$. At Natitingou, it varied between $39^{\circ} \mathrm{C}$ and $48.3^{\circ} \mathrm{C}$ with an average of $40.94^{\circ} \mathrm{C}$. At Parakou, TXx varied between $38^{\circ} \mathrm{C}$ and $41.6^{\circ} \mathrm{C}$ with an average of $39.74^{\circ} \mathrm{C}$. For all stations the index shows an increasing trend (Figure 2). This trend is statistically significant at the $95 \%$ confidence level at Kandi and Parakou where it increases by 0.1 and $0.3^{\circ} \mathrm{C}$ per decade respectively. On the other hand, at the $95 \%$ confidence level, the trend is not statically significant at Natitingou and the index increases by $0.2^{\circ} \mathrm{C}$ per decade.

TNn varied from $9.8^{\circ} \mathrm{C}$ to $14.9^{\circ} \mathrm{C}$ at Kandi, from $8.8^{\circ} \mathrm{C}$ to $16.9^{\circ} \mathrm{C}$ at Natitingou and from $12.6^{\circ} \mathrm{C}$ and $18.2^{\circ} \mathrm{C}$ at Parakou. Its mean are respectively $12.54^{\circ} \mathrm{C}$, $13.33^{\circ} \mathrm{C}$ and $15.6^{\circ} \mathrm{C}$ at these stations. TNn shows significant upward trends of $0.6^{\circ} \mathrm{C}$ per decade at Parakou, and non-significant of $0.1^{\circ} \mathrm{C}$ per decade at Kandi. A significant decrease trend of $0.7^{\circ} \mathrm{C} /$ decade of $\mathrm{TNn}$ is noted at Natitingou (Figure 2). The mean values of the diurnal thermal amplitude (DTA) are $12.8^{\circ} \mathrm{C}$, $12.62^{\circ} \mathrm{C}$ and $11.49^{\circ} \mathrm{C}$ respectively at Kandi, Natitingou and Parakou. DTR oscillates between $12.03^{\circ} \mathrm{C}$ and $13.89^{\circ} \mathrm{C}$ at Kandi; $10.61^{\circ} \mathrm{C}$ and $12.81^{\circ} \mathrm{C}$ at Parakou with significant downward trends of $0.07^{\circ} \mathrm{C}$ and $0.1^{\circ} \mathrm{C}$ per decade respectively. At Natitingou, DTR varies between $11.72^{\circ} \mathrm{C}$ and $13.94^{\circ} \mathrm{C}$ and shows a non-significant increase trend of $0.1^{\circ} \mathrm{C}$ per decade (Figure 2). For this group of indices, it can be seen that in Natitingou the TNn index is decreasing in contrast to the other stations where it is increasing, this is probably due to the relief of the region. Natitingou is a mountainous area with mountains that can reach up to 800 meters high. 


\section{Historic temperature intensity index (TXx, TNn and DTR) variation on BBFN for 1976-2019}

TXx Kandi

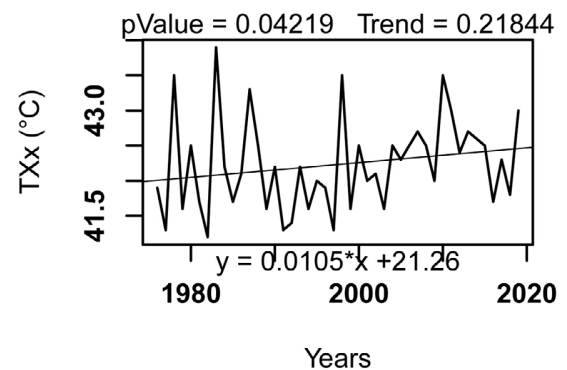

TNn Kandi

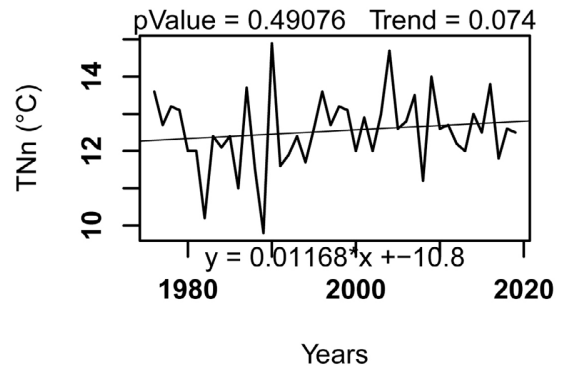

DTR Kandi

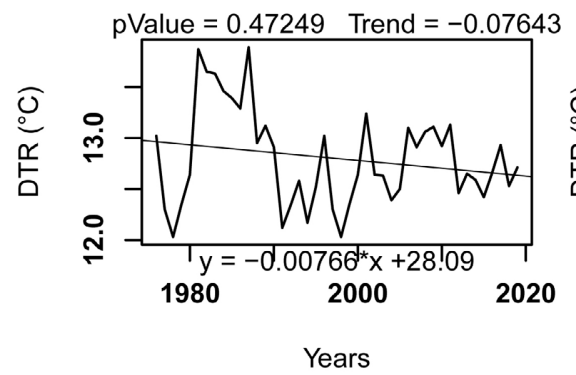

TXx Natitingou

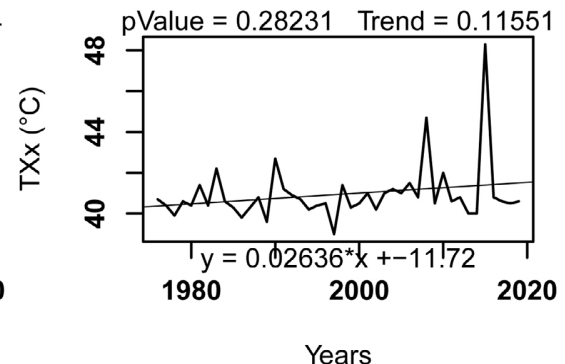

TNn Natitingou

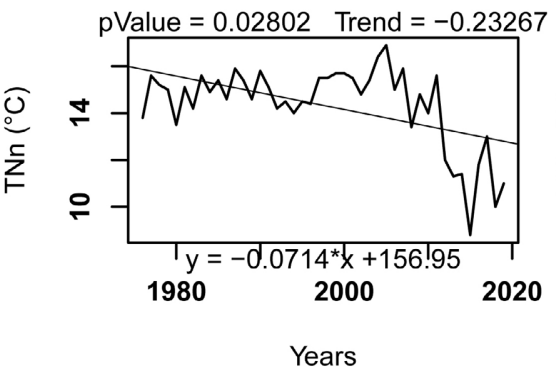

DTR Natitingou

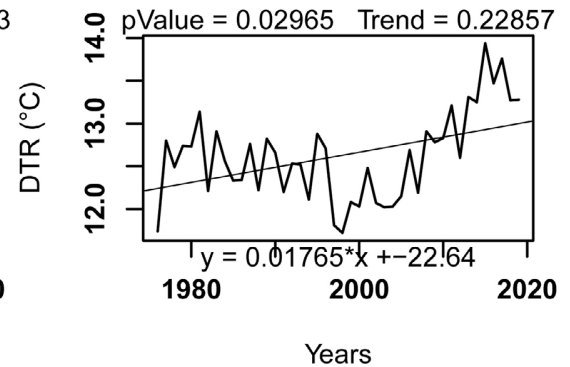

TXx Parakou

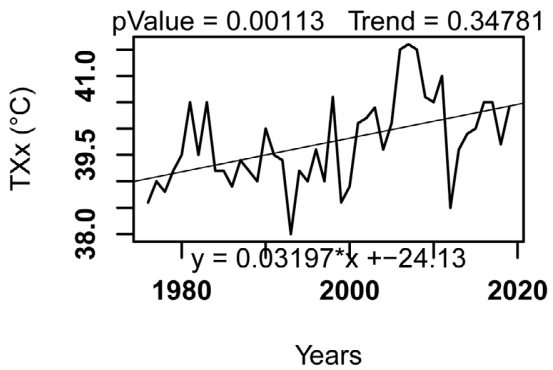

TNn Parakou

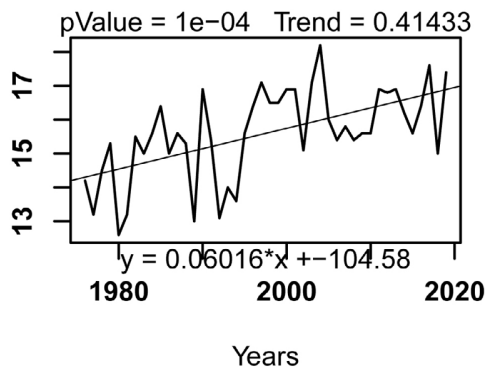

DTR Parakou

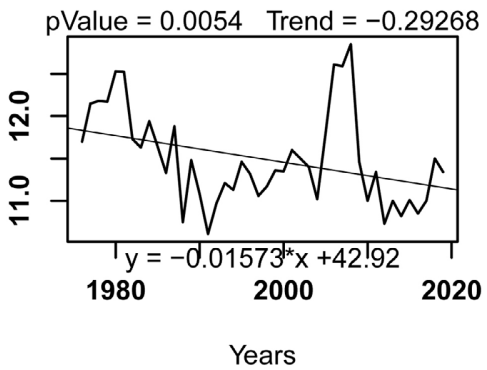

Figure 2. Trend of extreme temperature intensity observed.

CSDI remained zero during 1976 to 2019 at Kandi and Parakou except for the year 1983 (CSDI = 6 days) at Kandi and the years 1976 and 1977 (CSDI equal 20 and 7 days) for Parakou. In contrast, at Natitingou the CSDI varies between 0 and 89 days with a non-significant upward trend of 1 day per year (Figure 3 ).

WSDI (warm period duration indicator) varied between 0 and 32 days at Kandi with an average of 5.14 days; at Natitingou it varied between 0 and 30 days with an average of 4.7 days. At Parakou it varied between 0 and 120 days with an average of 12.75 days. Figure 3 shows significant upward trends for WSDI at Kandi and Parakou, which increase by 2 and 6 days per decade respectively. 


\section{Historic temperature frequency index (CSDI, WSDI, TX90p and TN90p)} variation on BBFN for 1976-2019
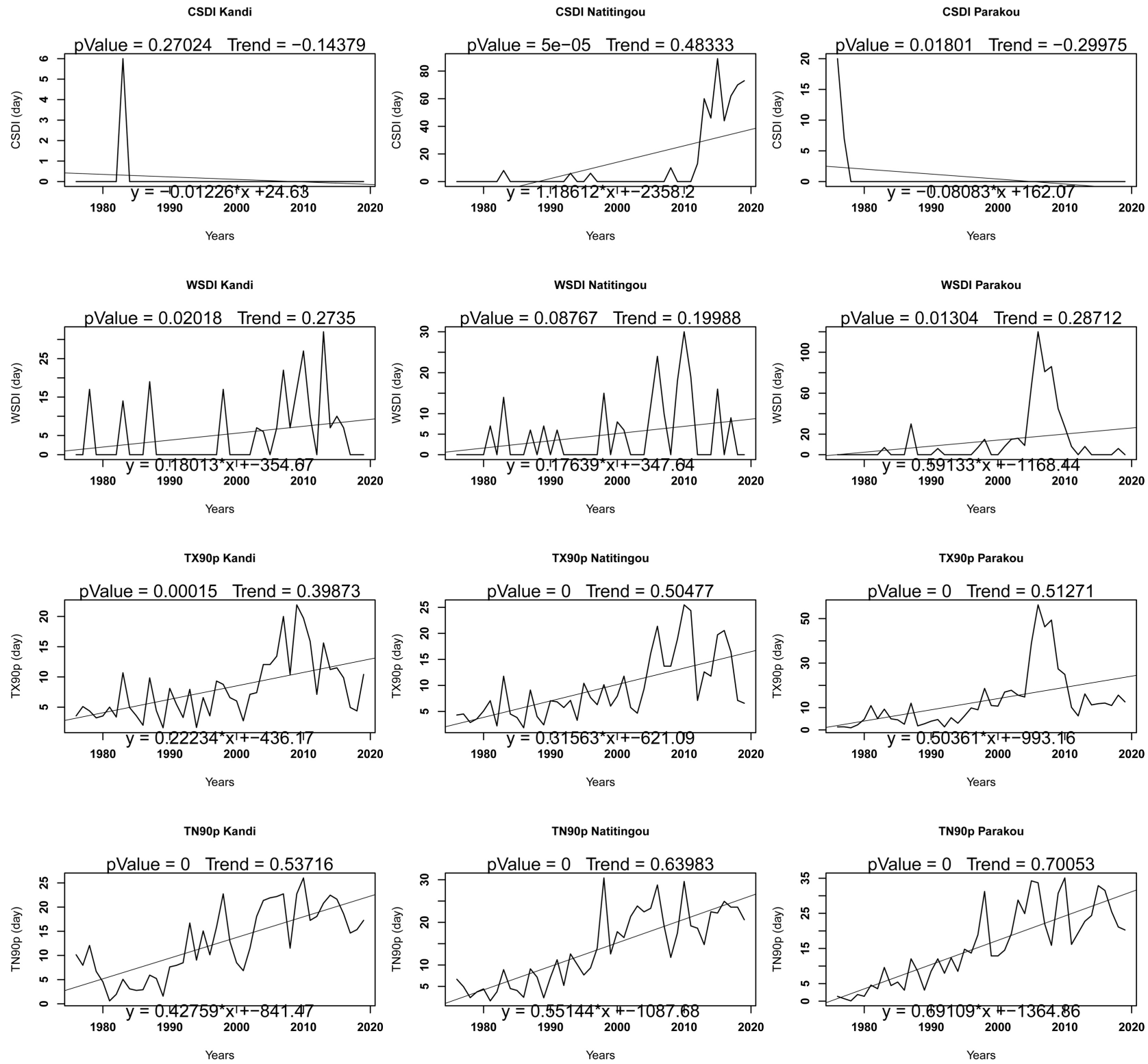

Figure 3. Trend of observed extreme temperature frequency.

At Natitingou, the trend for WSDI is rather non-significantly increasing by 1 day per decade (Figure 3 ).

TX90P varies between 1.59 and 21.91 days at Kandi; 1.86 and 25.46 days at Natitingou and 0.96 and 56.16 days at Parakou with mean values of 7.96; 9.38 and 12.81 days respectively. TX90p shows significant upward trends of 2, 3 and 5 days per decade at Kandi, Natitingou and Parakou respectively (Figure 3). At Natitingou, a non-significant increase trend of 5 days per decade is observed (Figure 3). TN90P varies between 0.6 and 26.03 days at Kandi; 1.41 and 30.59 days at Natitingou and 0.08 and 35.07 days at Parakou with mean values of 
12.65, 13.82 and 15.6 days respectively. TN90p shows significant upward trends of 4, 5 and 7 days per decade at Kandi, Natitingou and Parakou respectively (Figure 3).

\subsection{Projected Trends under RCP4.5 and RCP8.5 Scenarios}

Figure 4 shows non-significant increase trend of $0.3^{\circ} \mathrm{C}$ and $0.4^{\circ} \mathrm{C}$ per decade for TXx at Kandi under RCP4.5 and RCP8.5 scenarios respectively. At Natitingou increased trends are also noted. Under RCP4.5 the trend is not significant and is about $0.3^{\circ} \mathrm{C}$ per decade while, under RCP8.5, the trend is significant and is about

Future Temperature intensity index (TNn, TXx, and DTR) variation for 2021-2050 (RCP 4.5 and RCP 8.5)

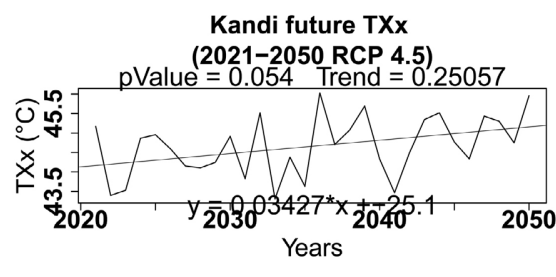

Kandi future TXX

(2021-2050 RCP 8.5)

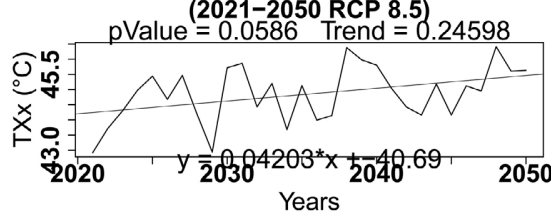

Kandi future $\mathrm{TNn}$

(2021-2050 RCP 4.5)

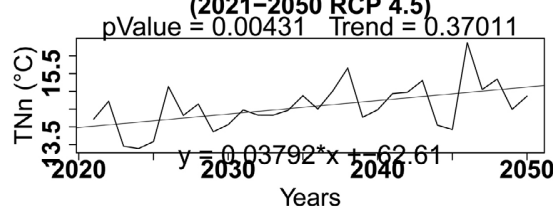

Kandi future TNn

(2021-2050 RCP 8.5)

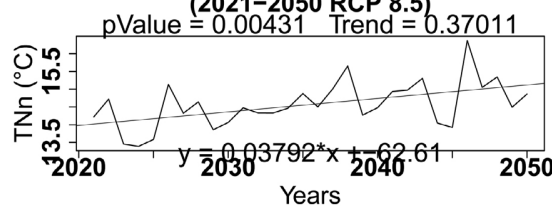

Kandi future DTR

(2021-2050 RCP 4.5)

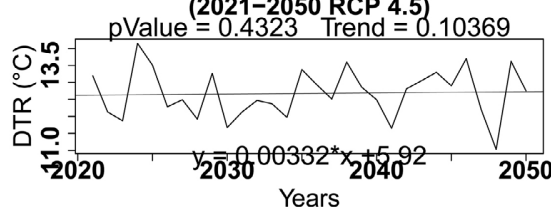

Kandi future DTR

(2021-2050 RCP 8.5)

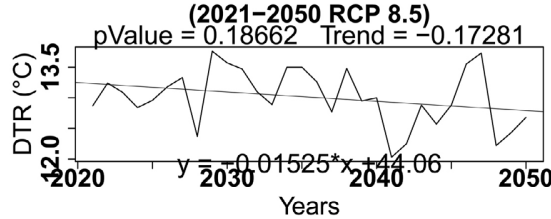

Natitingou future TXX

(2021-2050 RCP 4.5)

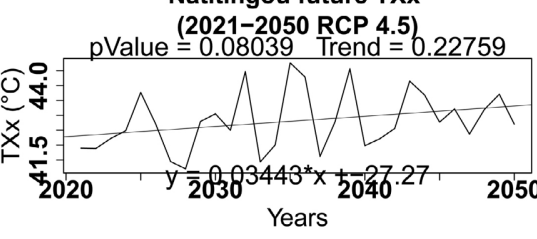

Natitingou future TXX

(2021-2050 RCP 8.5)

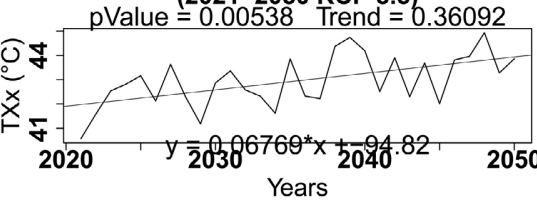

Years

Natitingou future TNn

(2021-2050 RCP 4.5

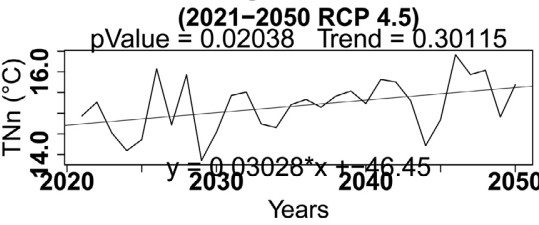

Natitingou future TNn

(2021-2050 RCP 8.5)

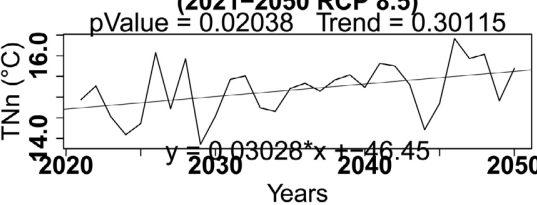

Natitingou future DTR

(2021-2050 RCP 4.5)

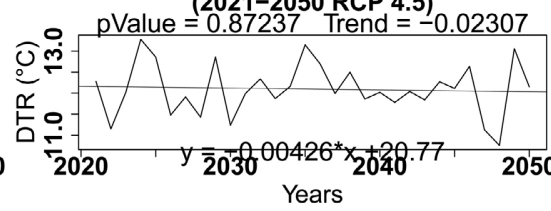

Natitingou future DTR

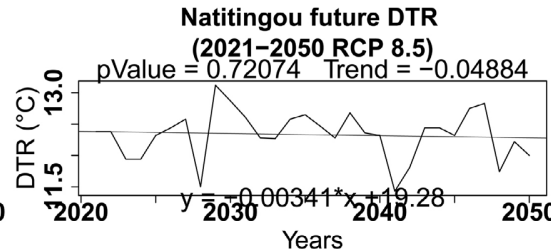

Parakou future TXX

(2021-2050 RCP 4.5

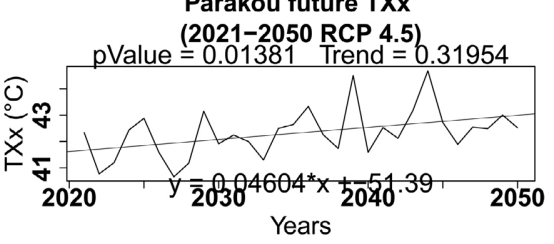

Parakou future TXX

(2021-2050 RCP 8.5)

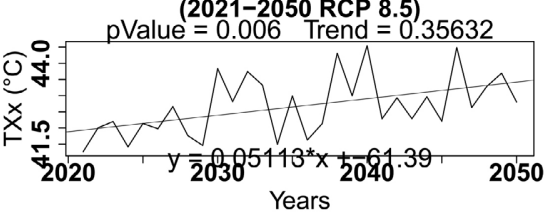

Years

Parakou future TNn

(2021-2050 RCP 4.5

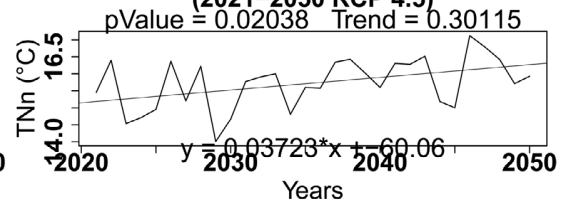

Parakou future TNn

2021-2050 RCP 8.5

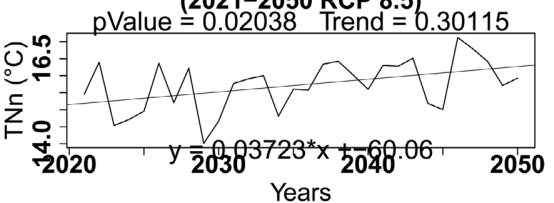

Parakou future DTR

(2021-2050 RCP 4.5

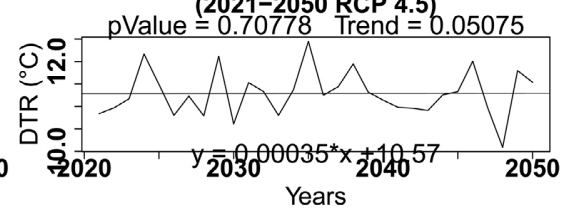

Parakou future DTR

(2021-2050 RCP 8.5)

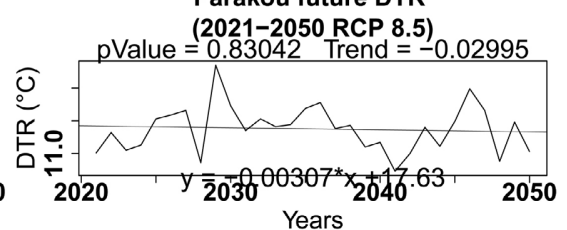

Figure 4. Projected trends of extreme temperature intensity. 
by $0.6^{\circ} \mathrm{C}$ per decade. Trends could significantly increase under both scenarios at Parakou for TXx. Increases of $0.46^{\circ} \mathrm{C}$ and $0.5^{\circ} \mathrm{C}$ per decade are noted for RCP4.5 and $\mathrm{RCP} 8.5$ respectively.

TNn shows significant upward trends under both RCP4.5 and RCP8.5 at all stations. These trends are $0.37^{\circ} \mathrm{C}, 0.30^{\circ} \mathrm{C}$ and $0.37^{\circ} \mathrm{C}$ per decade at Kandi, Natitingou and Parakou respectively.

At Natitingou, non-significant decrease trends of $0.04^{\circ} \mathrm{C}$ and $0.03^{\circ} \mathrm{C}$ per decade respectively under both RCP4.5 and RCP8.5 are expected for DTR (Figure 4). Non-significant increase trends of $0.03^{\circ} \mathrm{C}$ and $0.003^{\circ} \mathrm{C}$ per decade are observed at Kandi and Parakou for DTR under RCP4.5 while, under RCP8.5 non-significant decrease trends of $0.1^{\circ} \mathrm{C}$ and $0.03^{\circ} \mathrm{C}$ per decade at Kandi and Parakou (Figure 4) are projected.

Figure 5 shows that CSDI decreases significantly regardless of the station and considered scenario. Under RCP4.5 scenario, we note a decrease of 3, 4 and 6 days per decade at Kandi, Natitingou and Parakou respectively. Under RCP8.5 scenario, a decrease of 3, 4 and 5 days per decade are noted at Kandi, Natitingou and Parakou respectively (Figure 5). WSDI shows significant upward trends of 11, 5 and 4 days per decade respectively at Kandi, Natitingou and Parakou under RCP4.5 scenario (Figure 5). Under RCP8.5 scenario non-significant trends are noted for all stations. These increase trends are 4, 5 and 3 days per decade respectively at Kandi, Natitingou and Parakou (Figure 5).

TN90p shows significant increase trends for all stations and for all scenarios. Increase trends of 8, 6 and 7 days per decade are noted respectively at Kandi, Natitingou and Parakou under RCP4.5. Under RCP8.5, these trends are 8, 6 and 8 days per decade respectively (Figure 5). TX90p shows significant upward trends of 3, 4 and 3 days per decade at Kandi, Natitingou and Parakou respectively under RCP8.5 (Figure 5). For RCP4.5, TX90p shows significant increase trends at Kandi and Parakou and non-significant trends at Natitingou. These increase trends, are 5, 2 and 3 days per decade respectively at Kandi, Natitingou and Parakou under RCP4.5 (Figure 5).

\subsection{Changes in Extreme Temperature Indices}

Figure 6 shows changes of extreme temperature index under RCP4.5 and RCP8.5 emission scenarios (2021-2050) compared to the baseline period (1990-2019). From this figure, it can be seen that for the next 30 years, the maximum temperature (TXx) and minimum temperature (TNn) could increase under both RCP4.5 and RCP8.5 scenarios. For TXx, the increase could be $2.4,1.9^{\circ} \mathrm{C}$ and $2.6^{\circ} \mathrm{C}$ respectively at Kandi, Natitingou and Parakou under RCP4.5 scenario while it could be $2.6^{\circ} \mathrm{C}, 2^{\circ} \mathrm{C}$ and $2.9^{\circ} \mathrm{C}$ respectively at Kandi, Natitingou and Parakou under RCP8.5 scenario. TXx change is significant for both scenarios and all stations (Table 3 ). The minimum temperatures (TNn), indicate an increase of $2^{\circ} \mathrm{C}, 0.8^{\circ} \mathrm{C}$ and $0.1^{\circ} \mathrm{C}$ respectively at Kandi, Natitingou and Parakou under both RCP4.5 and RCP8.5 scenarios. Under both scenarios, TNn shows 
Future Temperature frequency index (WSDI, CSDI, TN90p and TX90p) variation for 2021-2050 (RCP 4.5 and RCP 8.5)
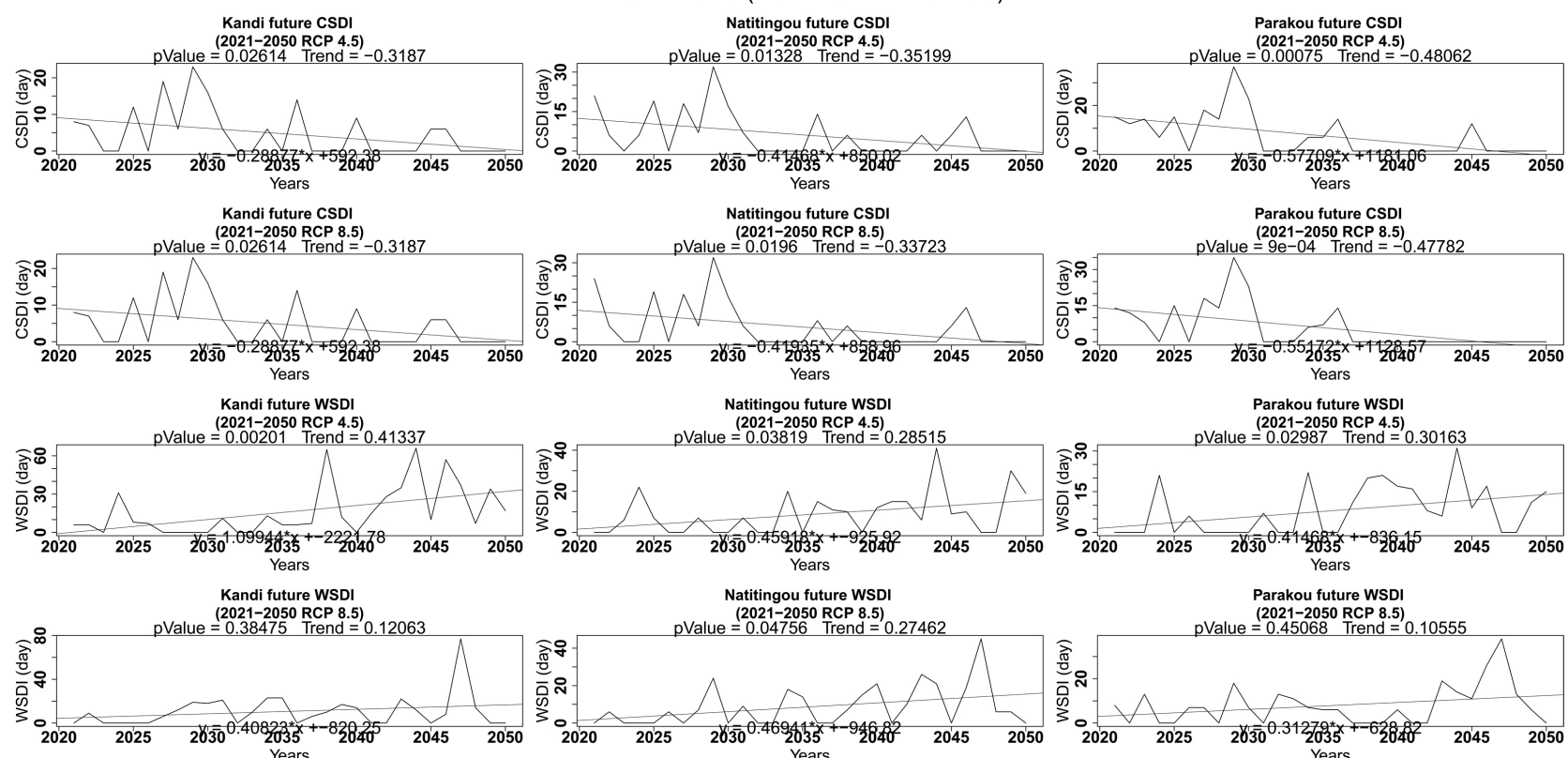

Natitingou future WSD pValue $=0.04756$ Trend $=0.27462$

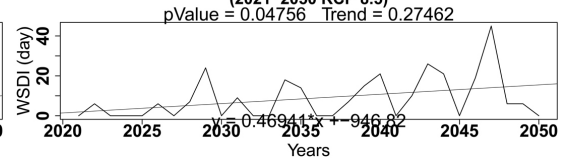

arakou future WSD

pValue $=0.45068$ Trend $=0.10555$

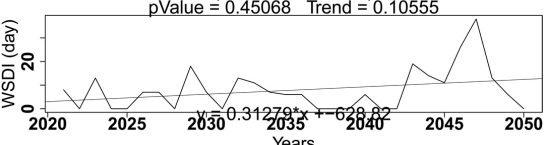

Kandi future TN90

pValue $=0$ Trend $=0.6046$

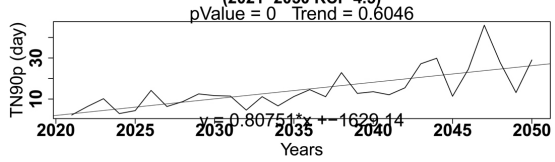

Natitingou future TN90p

pValue $=0.00017$ Trend $=0.48792$

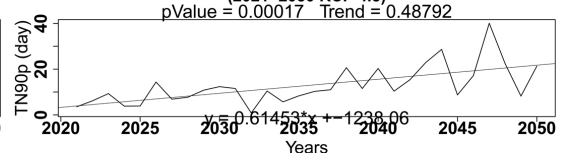

Parakou future TN90p

2021-2050 RCP 4.5

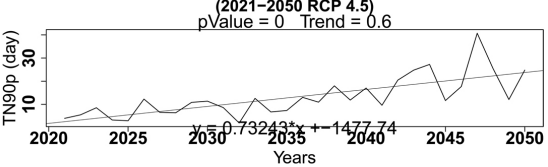

Natitingou future TN90p pValue $\stackrel{(2021-2050 \text { RCP }}{=} 8 \mathrm{e}-05$ Trend $=0.51093$
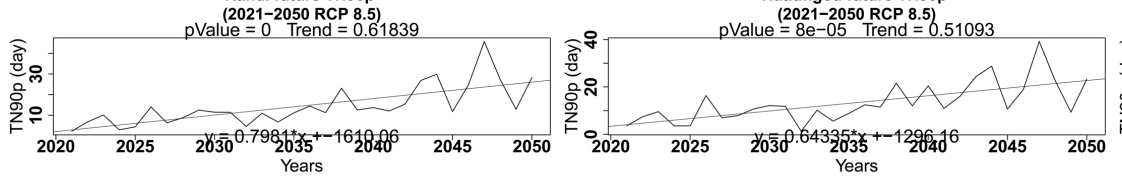

Parakou future TN90p

$\stackrel{(2021-2050 \text { RCP } 8.5}{=} 1 \mathrm{e}-05$ Trend $=0.58621$

Kandi future TX90p

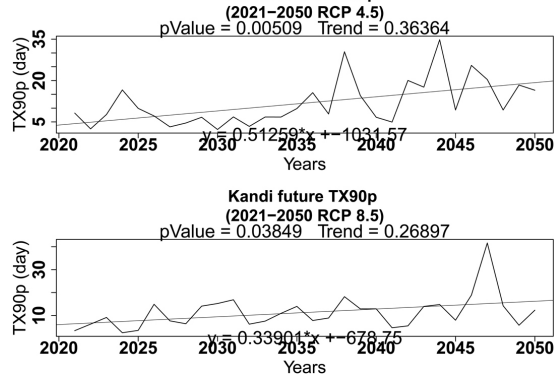
(2021-2050 RCP 4.5)

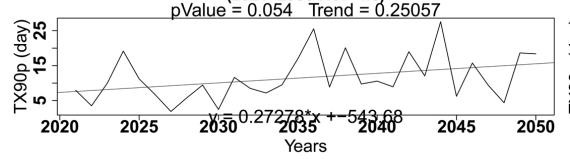
Trend $=0.25057$

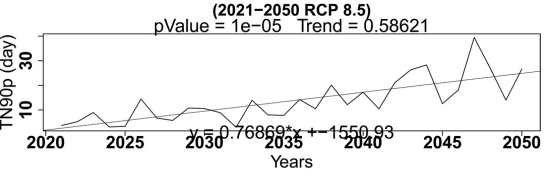

Parakou future TX90p

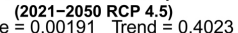
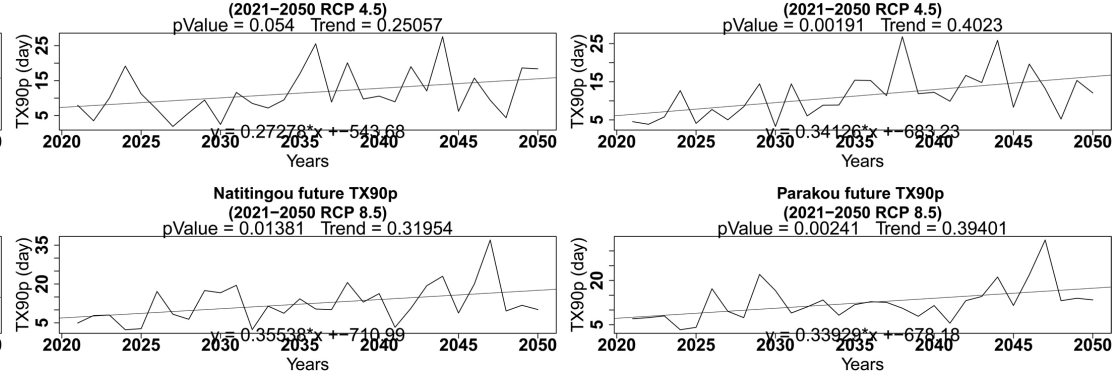

Figure 5. Projected trend of extreme temperature frequency.

significant changes at Kandi and Parakou and not significant at Natitingou (Table 3). DTR shows a decrease of $0.1^{\circ} \mathrm{C}, 0.5^{\circ} \mathrm{C}$ and $0.2^{\circ} \mathrm{C}$ respectively at Kandi, Natitingou and Parakou under RCP4.5 compared to the reference period. Under RCP8.5, a decrease of $0.3^{\circ} \mathrm{C}$ and $0.1^{\circ} \mathrm{C}$ is noted respectively at Natitingou and Parakou compared to the reference period. At Kandi, RCP8.5 shows an increase of $0.2^{\circ} \mathrm{C}$ compared to the baseline period. DTR shows significant changes at Natitingou and Parakou under both scenarios (Table 3).

At Kandi, all extreme temperature frequency indices (WSDI, CSDI, TX89p and TN90p) increase under both RCP4.5 and RCP8.5 scenarios compared to the 


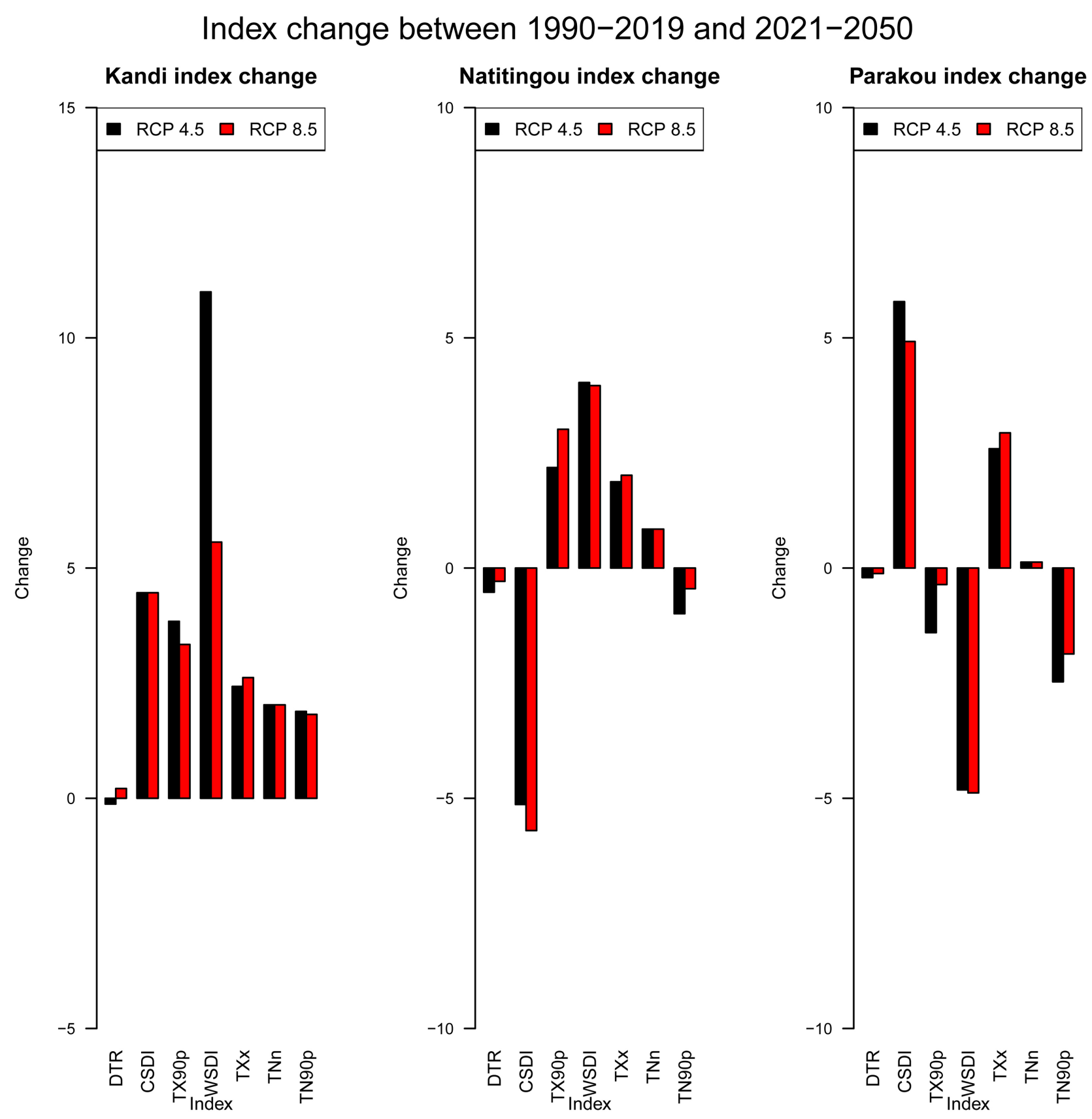

Figure 6. Differences between the projections and the reference period.

reference period. There are deviations of $4,11,4$ and 2 days respectively for CSDI, WSDI, TX90p and TN90p under RCP4.5 compared to the baseline period (Figure 6) while under RCP8.5 these differences are respectively 4, 5, 3 and 2 days compared to the reference period (Figure 6). At Natitingou, TX90p and WSDI will increase under both RCP4.5 and RCP8.5 scenarios. There are respectively an increase of 2 and 4 days under RCP 4.5 and 3 and 4 days under RCP8.5 compared to the baseline period (Figure 6). At this station, TN90p and CSDI could decrease under both RCP4.5 and RCP8.5 compared to the baseline period. The decrease could be of 5 and 1 days for RCP4.5 and 6 and 0.4 days for RCP8.5 
Table 3. Significance of changes in temperature indices.

\begin{tabular}{ccccccc}
\hline \multirow{2}{*}{ Index name } & \multicolumn{3}{c}{ RCP4.5 } & & \multicolumn{3}{c}{ RCP8.5 } \\
\cline { 2 - 7 } & Kandi & Natitingou & Parakou & Kandi & Natitingou & Parakou \\
\hline DTR & 0.88145 & 0.88844 & $\mathbf{0}$ & $\mathbf{0 . 0 0 0 9 3}$ & $\mathbf{0 . 0 1 0 4 6}$ & $\mathbf{0}$ \\
CSDI & $\mathbf{0 . 0 0 0 2 7}$ & $\mathbf{0 . 0 3 3 0 1}$ & $\mathbf{0 . 0 0 0 2 7}$ & $\mathbf{0 . 0 0 0 2 7}$ & $\mathbf{0 . 0 3 3 0 1}$ & $\mathbf{0 . 0 0 0 2 7}$ \\
TX90p & 0.20152 & 0.8812 & 0.10755 & 0.27913 & 0.90129 & 0.06872 \\
WSDI & $\mathbf{0 . 0 1 0 7}$ & $\mathbf{0 . 0 0 9 5 9}$ & 0.84178 & 0.13427 & 0.1232 & 0.28422 \\
TXx & $\mathbf{0}$ & $\mathbf{0}$ & $\mathbf{0}$ & $\mathbf{0}$ & $\mathbf{0}$ & $\mathbf{0}$ \\
TNn & $\mathbf{0}$ & 0.19651 & $\mathbf{0}$ & $\mathbf{0}$ & 0.19651 & $\mathbf{0}$ \\
TN90p & 0.42063 & 0.10881 & $\mathbf{0 . 0 0 9 0 6}$ & 0.39969 & 0.10054 & $\mathbf{0 . 0 0 8 0 9}$ \\
\hline
\end{tabular}

compared to the baseline period. At Parakou, the extreme heat frequency index (WSDI, TX90p and TN90p) could be decreased under both RCP4.5 and RCP8.5 scenarios compared to the baseline period. The extreme cold temperature frequency index (CSDI) could be increase under both RCP4.5 and RCP8.5 scenarios compared to the baseline period. For the extreme heat frequency index (WSDI, TX90p and TN90p), there are respective an increase of 5, 1 and 2.5 days under RCP4.5 and 5, 0.4 and 2 days under RCP8.5. The CSDI shows an increase of 6 and 5 days respectively under RCP4.5 and RCP 8.5 compared to the baseline period (Figure 6). Also for this index group, a warming of the basin is indicated for future years as warm sequences increase more than cold sequences. From Table 3, it can be seen that CSDI shows significant changes regardless of the scenario and the station. The changes in WSDI remain significant under RCP4.5 at Kandi and Natitingou. TN90p shows significant changes only at Parakou and under both scenarios.

\section{Discussion}

In summary, there are increasing variations on the extreme temperature intensity index for all the stations considered over the historical period. These results are confirmed by Badou (2016) who showed that temperatures in the basin have increased. Gnanglè et al. (2011) also found the same results for the three climatic zones of Benin. New et al. (2006) also showed increases of 0.179 and $0.160^{\circ} \mathrm{C} /$ decade respectively for TXx and TXn indices for West and South Africa. Mahamoud et al. (2011) found the same results for Djibouti. Tramblay et al. (2005), also confirm the same case for the Gulf of St. Lawrence River. For the whole study period, we count for these indices on average a warming of about $2.27^{\circ} \mathrm{C}$.

The averages of WSDI index show significant upward trends for all stations, while CSDI is decreasing at all stations except Natitingou where it is increasing. This means that the warm sequences are increasing at the expense of the cold sequences in the Beninese basin of the Niger River. This was obtained by New et al. (2006) for southern and western Africa. Furthermore, the extreme heat fre- 
quency indices (TX90p and TN90p) have increasing trends. This reflects that the occurrence of the number of hot days and hot nights have increased. This situation has led the basin to heat. This was confirmed by Badou in 2016 for mean temperatures. New et al. (2006) have the same conclusions for southern and western Africa. It should also be noted that these indices show very significant variations. This is also in line with the results of Gnanglè et al. (2011).

The projected trends (2021-2050) in TXx (maximum temperature maxima), TNn (minimum temperature minima), and DTR (temperature range) could increase by about $0.45^{\circ} \mathrm{C} /$ decade for both RCP 4.5 and RCP 8.5 scenarios. This increase was $0.3^{\circ} \mathrm{C}$ per decade for the baseline period (1990-2019). The warming that began in the recent past over the basin will continue until 2050 with an increase of about $0.15^{\circ} \mathrm{C}$ depending on the scenario. This warming was predicted for the study basin by Badou (2016) based on average temperatures. Obada (2017), again using average temperatures confirmed the same results. These results are indicated for all of West Africa by the IPCC (2013). This situation seems global because confirmed on other regions such as the Seine (GICC-RexHySS, 2011) where it is expected increases in average temperatures of $1.5^{\circ} \mathrm{C}$ to $3^{\circ} \mathrm{C}$ by 2050 and $2^{\circ} \mathrm{C}$ to $4.5^{\circ} \mathrm{C}$ by 2100 .

The trends of TN90p (number of hot nights) and TX90p (number of hot days) show an increase over the period 2021-2050, regardless of the model scenario. These indices show increases in hot days at Kandi and Natitingou and decreases at Parakou; and decreases in hot nights at the three stations and according to the two scenarios with more critical situations using RCP8.5 than using RCP4.5. In fact, increases of about 7 and 3 days per decade are predicted for TN90p and TX90p, respectively, during the projected period; while increases of 5 and 4 days per decade, respectively, are observed for baseline period. WSDI shows the same trends as TXx. It increases by about 5.2 days per decade under both the RCP4.5 and RCP8.5 scenarios. This increase was about 2.7 days per decade for the baseline period. WSDI shows an average rate of increase of $42 \%$ over the baseline period. Extreme temperature intensity indices (TXx and TNn) and extreme heat frequency indices (WSDI and TX90p) are projected to increase over the study basin. This will most certainly lead to the basin warming more than it has in the past. It is therefore important that scientists, local, national and international decision makers at various levels take optimal and collegial resolutions to counteract the adverse effects of this phenomenon. It is also important to note that not all these indices show significant changes. Only the TXx and CSDI indices change significantly. This reflects that these indices vary more than the other one.

\section{Conclusion}

The results obtained on intensity and frequency extreme temperature index for the Beninese basin of the Niger River, confirm the same climatic changes observed in Benin and in West Africa in general in previous works. Almost all the 
calculated indices present worrying situations for the future of the basin. Indeed, the indices of extreme temperature intensity (TNn, TXx, and DTR), those related to the frequency of hot sequences (WSDI and TX90p) tend to increase. In contrast, the cold sequence frequency index (CSDI) is decreasing. Most disturbing is that both regional climate model scenarios used in this study indicate that the deteriorated climate conditions of the recent past will continue for the next 30 years. Statistically significant changes are noted for the TXx and CSDI. It is therefore up to each party to play an effective role in mitigating the consequences. It should also be noted that the change is more pronounced with the RCP8.5 scenario than with RCP4.5 in the model used.

\section{Conflicts of Interest}

The authors declare no conflicts of interest regarding the publication of this paper.

\section{References}

AMMA ISSC (2005). The International Science Plan for AMMA, Final Version, May 2005.

Badara, S. A., \& Camara, M. (2017). Evolution Des Indices Pluviométriques Extrêmes Par L'analyse De Modèles Climatiques Régionaux Du Programme CORDEX: Les Projections Climatiques Sur Le Sénégal. European Scientific Journal, 13, 206. https://doi.org/10.19044/esj.2017.v13n17p206

Badou, F. D. (2016). Multi-Model Evaluation of Blue and Green Water Availability under Climate Change in Four-Non Sahelian Basins of the Niger River Basin (155 p). These de Doctorat, University of Abomey-Calavi (UAC), Institut National de l'Eau (INE).

Bush, M., \& Flenley, J. (2007). Tropical Rainforest Responses to Climatic Change (225 p). Springer. https://doi.org/10.1007/978-3-540-48842-2

Frei, C. (2008). Analysis of Climate and Weather Data. Federal Office of Meteorology and Climatology, Meteo Schweiz.

GICC-RexHySS (2011). Résultat de projet, programme piren-seine, Programme Interdisciplinaire de Recherche sur l'Environnement de la Seine, Impact du changement climatique sur les ressources en eau du bassin versant de la Seine.

Gnanglè, C. P., Glèlè Kakaï, R., Assogbadjo, A., Vodounnon, S., Yabi, J. A., \& Sokpon, N. (2011). Tendances climatiques passées, modélisation, perceptions et adaptations locales au Benin. Climatologie, 8, 27-40. https://doi.org/10.4267/climatologie.259

Graham, L. P., Andréasson, J., \& Carlsson, B. (2007). Assessing Climate Change Impacts on Hydrology from an Ensemble of Regional Climate Models, Model Scales and Linking Methods-A Case Study on the Lule River basin. Climatic Change, 81, 293-307. https://doi.org/10.1007/s10584-006-9215-2

Haidu, I. (2009). Extrêmes climatiques : genèse modélisation et impacts, Numéro spécial dédié au XXIIème colloque de l'association internationale de climatologie, 90ème anniversaire de l'Université Romaine de Cluj.

IPCC (2007). Climate Change 2007: The Physical Science Basis. Contribution of Working Group I to the Fourth Assessment Report of the Intergovernmental Panel on Climate Change.

IPCC (Intergovernmental Panel on Climate Change) GIEC (2013). Changements climatiques en 2013, Les éléments scientifiques, résumé à l'intention des décideurs, service 
d'appui.

Jacob, D., Bärring, L., Christensen, O. B., Christensen, J. H., Hagemann, S., Hirschi, M., Kjellström, E., Lenderink, G., Rockel, B., Schär, C., Seneviratne, S.I., Somot, S., van Ulden, A., \& van den, Hurk B. (2007). An Inter-Comparison of Regional Climate Models for Europe: Design of the Experiments and Model Performance. Climatic Change, 81, 31-52. https://doi.org/10.1007/s10584-006-9213-4

Janicot, S., Thorncroft, C., Ali, A., Asencio, N., Berry, G., Bock, O., Bourlès, B., Caniaux, G., Chauvin, F., Deme, A., Kergoat, L., Lafore, J.-P., Lavaysse, C., Lebel, T., Marticorena, B., Mounier, F., Nedelec, P., Redelsperger, J.-L., Ravegnani, F., Reeves, C. E., Roca, R., De Rosnay, P., Schlager, H., Sultan, B., Tomasini, M., \& Ulanovsky, A. (2008). Large-Scale Overview of the Summer Monsoon over West Africa during the AMMA Field Experiment in 2006. Annales Geophysicae, 26, 2569-2595. https://doi.org/10.5194/angeo-26-2569-2008

Lafon, T., Dadson, S., Buys, G., \& Prudhomme, C. (2013). Bias Correction of Daily Precipitation Simulated by a Regional Climate Model: A Comparison of Methods. International Journal of Climatology, 33, 1367-1381. https://doi.org/10.1002/joc.3518

Leggett, J., Pepper, W. J., \& Swart, R. J. (1992). Emissions Scenarios for IPCC: An Update. In J. T. Houghton, B. A. Callander, \& S. K. Varney (Eds.), Climate Change 1992. The Supplementary Report to the IPCC Scientific Assessment (pp. 69-95). Cambridge University Press.

Mahamoud, A., Manzo, O. L., \& Ozer, P. (2011). Évolution récente des extrêmes pluviométriques et des températures à Djibouti.

Moore, K., Pierson, D., Pettersso, K., Schneiderman, E., \& Samuelsson, P. (2008). Effects of Warmer World Scenarios on Hydrologic Inputs to Lake Mälaren, Sweden and Implications for Nutrient Loads. Hydrobiologia, 599, 191-199.

https://doi.org/10.1007/s10750-007-9197-8

New M., Hewitson, B., Stephenson, D. B., Tsiga, A., Kruger, A., Manhique, A., Gomez, B., Coelho, C. A. S., Masisi, D. N., Kululanga, E., Mbambalala, E., Adesina, F., Saleh, H., Kanyanga, J., Adosi, J., Bulane, L., Fortunata, L., Mdoka, M. L., \& Lajoie, R. (2006). Evidence of Trends in Daily Climate Extremes over Southern and West Africa. Journal of Geophysical Research, 111, D14102. https://doi.org/10.1029/2005JD006289

Obada, E. (2017). Approche de quantification des changements récents et futurs de quelques paramètres hydro-climatiques dans le bassin de la Mékrou (Bénin) (212 p). Univerté d'Abomoy-Calavi, ICMPA.

Rajczak, J. (2016). Robust Climate Scenarios for Sites with Sparse Observations: A Two-Step Bias Correction Approach. International Journal of Climatology, 36, 1226-1243. https://doi.org/10.1002/joc.4417

Saurwein, D. (2016). Analyse des tendances passées et futures de variables météorologiques pour des stations de mesure de moyenne et haute altitude en Suisse (74 p). Rapport $3 \mathrm{e}$ année $\mathrm{BSc}$, TRP.

Sperna Weiland, F. C., van Beek, L. P. H., Kwadijk, J. C. J., \& Bierkens, M. F. P. (2010). The Ability of a GCM-Forced Hydrological Model to Reproduce Global Discharge Variability. Hydrology and Earth System Sciences, 14, 1595-1621.

https://doi.org/10.5194/hess-14-1595-2010

Tramblay, Y., Gachon, P., Saint-Hilaire, A., \& Chaumont, D. (2005). Variabilité et extrêmes de température et de précipitation entre 1941 et 2000: Le cas du golfe du fleuve saint Laurent. INRS-ETE, rapport de recherche R-805.

Zhang, X. B., \& Yang, F. (2004). RClimDex (1.0), User Manual, Climate Research Branch, Environment Canada (23 p). Downsview. 